\title{
Consumer perception of the sustainability of dairy products and plant-based dairy alternatives
}

\author{
A. N. Schiano, ${ }^{1}$ W. S. Harwood, ${ }^{1}$ P. D. Gerard, ${ }^{2}$ () and M. A. Drake ${ }^{1 *}$ \\ ${ }^{1}$ Department of Food, Bioprocessing and Nutrition Sciences, Southeast Dairy Foods Research Center, North Carolina State University, \\ Raleigh 27695 \\ ${ }^{2}$ School of Mathematical and Statistical Sciences, Clemson University, Clemson, SC 29634
}

\begin{abstract}
Plant-based dairy alternative beverage sales have increased in recent years. Plant-based dairy alternatives often advertise on a platform of sustainability and environmental commitment. To successfully position and market dairy products in this competitive environment, dairy companies must understand the consumer definition of and importance placed on sustainability, as well as communicate sustainability information effectively. The objective of this study was to characterize consumer perception of the sustainability of milk and dried dairy ingredients and their respective plant-based alternatives. Focus groups and 2 online surveys were conducted. In the first survey, maximum difference scaling was used to rank the importance of specific dairy product attributes to sustainability, along with an exercise in which respondents selected whether a fluid milk or protein powder product was sustainable. A follow-up survey included 2 exercises in which respondents selected whether generic dairy products or dried dairy ingredients were sustainable, natural, healthy, trustworthy, or ethical. Over half of dairy product consumers reported that they looked for sustainability-related information. Consumers who purchased both plant-based dairy alternative and dairy products placed a higher self-reported importance on sustainability than those who purchased dairy products only. Focus group and survey maximum difference scaling results identified 5 key attributes for sustainability: minimal carbon footprint/greenhouse gas emissions, few/no preservatives, animal happiness and welfare, and simple/minimal ingredients. Plant-based dairy alternatives followed by fluid milk and protein powders were considered more sustainable than dairy products, but package type and organic status also played a role
\end{abstract}

Received February 20, 2020.

Accepted July 23, 2020.

*Corresponding author: mdrake@ncsu.edu in consumer sustainability perception. Product labels were the most common source of sustainability information, although consumers also sought information on websites affiliated and unaffiliated with dairy companies. There was cognitive overlap among the terms sustainable, natural, healthy, ethical, and trustworthy as they relate to dairy products, but consumers used the terms distinctly. Consumers perceived differences in these terms between general categories of dairy as well as among products in a specific dairy category. Dairy companies may be able to differentiate themselves by helping consumers make these choices by simplifying sustainability-related messaging and by maintaining open, transparent communication regarding sustainability.

Key words: sustainability, milk, plant-based dairy alternatives, consumer surveys, qualitative research

\section{INTRODUCTION}

Plant-based dairy alternative beverage (PBDA) sales have increased in recent years. Currently, $7.4 \%$ of the total milk market share is made up of PBDA, a number expected to more than double to $18.5 \%$ by 2023 (Mintel Group Ltd., 2019a). Meanwhile, sales of some traditional dairy products are declining or stagnating, such as fluid milk (15\% decline since 2012; Mintel Group Ltd., 2019a). More than half of dairy consumers also purchase PBDA (Baertlein, 2015; Mintel Group Ltd., 2019a). In 2018, plant-based milk sales increased by $9 \%$ whereas cow milk sales decreased by $6 \%$ (Plant Based Foods Association, 2018). Growth of other PBDA was $50 \%$, primarily driven by a $131 \%$ increase in sales of plant-based coffee creamer (Plant Based Foods Association, 2018). Additional heavy growth was documented for plant-based alternatives to yogurt ( $55 \%$ increase), ice cream (38\% increase), and cheese ( $43 \%$ increase) (Plant Based Foods Association, 2018).

Messaging surrounding PBDA often involves sustainability, commitment to the environment, elimination of "unnatural foods," or humane treatment of animals, 
which may give them an advantage against traditional dairy products (Franklin-Wallis, 2019; Crawford, 2020). On-package, in-store, and digital media marketing for PBDA emphasizes how these new products are different enough from dairy to address consumer concerns, yet similar enough to provide the experience consumers expect and serve as a direct replacement (Fuentes and Fuentes, 2017). As concerns regarding sustainability grow, dairy products are beginning to market with related claims; for example, $21 \%$ of dairy milk products in 2018 launched with a grass-fed term (Mintel Group Ltd., 2019a). An August 2018 Mintel survey found $49 \%$ of internet users $18+$ yr of age worried about the environmental impact of dairy production, and $27 \%$ of the same consumers were willing to pay more for cheese made with milk from "free-range" cows (Mintel Group Ltd., 2019b). McCarthy et al. (2017) conducted a conjoint survey with means-end-chain interviews with both dairy and nondairy consumers. They found that a unique value ladder among nondairy consumers was that the plant-based attribute led to moral responses based on animal treatment and environmental effects. To successfully position and market dairy products, dairy companies must fully understand the consumer definition of and importance placed on sustainability. Furthermore, dairy companies must find a way to communicate sustainability information in a way that is understandable, believable, and authentic.

Unfortunately, there may be a mismatch between consumer and industry definitions of dairy foods sustainability. Whereas the industry tends to consider sustainability from a farm perspective, consumers may primarily view sustainability from a food perspective. According to the United Nations, sustainable development includes 3 types of strategies: economic (profit), social (people), and environmental (planet) (United Nations Department of Economic and Social Affairs, 2015). Ecological sustainability, typically the focus of dairy industry efforts, involves preserving the environment and using natural resources responsibly (United Nations Department of Economic and Social Affairs, 2015). However, consumers may place greater emphasis on the other aspects of sustainability - the social and economic aspects of how food production benefits consumers and industry employees, and how food production affects the wellbeing of people and animals. Peano et al. (2019) identified 5 clusters of consumers based on food sustainability definitions. Whereas one cluster of respondents defined the concept of food sustainability primarily by the effect of production on the environment and ecological balance, other clusters prioritized aspects such as social welfare, access to safe and healthy food, and local sourcing of foods.
Some work has been done to understand consumer perception of sustainability, but many unknowns remain including the value and trade-off of perceived sustainability and how or if sustainability beliefs are product dependent. Previous research has shown that consumers place different importance on sustainability-related attributes for different product categories, yet little research has been done to understand differences within the dairy product category (Bernués et al., 2003; Verain et al., 2016). These related attributes are also sources of growing concern for consumers. An August 2019 Mintel survey of internet users $18+$ yr of age who were purchasing less dairy milk than the previous year found $16 \%$ of respondents cited "I don't think it's healthy" and $8 \%$ of respondents cited "for animal welfare reasons" as reasons for reduced purchase (Mintel Group Ltd., 2019a). Furthermore, the relationship among consumer perception of sustainability and consumer perception of other related attributes, such as whether a product is natural, healthy, ethical, or trustworthy, is critical knowledge for effective consumer messaging for dairy foods. If there is significant overlap between consumer perceptions of sustainability and terms such as healthy, natural, trustworthy, and ethical, this can be taken into consideration when marketing dairy products to more effectively communicate their benefits.

Pelletier et al. (2013) demonstrated that young adults in Twin Cities, Minnesota, who placed higher importance on sustainable food production generally had better quality dietary patterns, indicating potential overlap between concepts of sustainability and a healthy diet. Verain et al. (2016) found healthiness and sustainability were synergistically perceived by Dutch consumers across a variety of food categories, including the general dairy category. This result suggests a possible halo effect in which perception of sustainability creates a favorable impression that increases perception of healthiness, and vice versa. Furthermore, consumer concepts of sustainability, health, and naturalness have been found to overlap in the case of organic products (Aschemann-Witzel, 2015). Consumers assume organic dairy products are inherently healthier, more natural, better for the environment, and better for animal welfare then their conventional counterparts, even when there is no significant evidence to confirm this statement (Ellis et al., 2009; Napolitano et al., 2010; Harwood and Drake, 2018; Merlino and Blanc, 2019).

Qualitative research and online surveys allow us to probe into underlying consumer perceptions of sustainability and related concepts. Focus groups and online surveys are often used to collect data regarding consumer perceptions of commercial products. Focus groups, which have been conducted extensively for 
dairy products, allow for a deep dive into consumer opinion and the collection of open-ended data which can direct further survey or product development (Thompson et al., 2007a,b; Jo et al., 2018; Speight et al., 2019). Online surveys allow for collection of both quantitative and qualitative data from a large number of consumers across many geographic areas. Specialized survey methods, such as maximum difference (MaxDiff) scaling, allow for direct comparison of the importance of individual attributes to overall consumer perception and have been used to study dairy products including fluid milk and cheese shreds (Harwood and Drake, 2018; Speight et al., 2019).

To compete with PBDA, dairy food producers must understand how to strategically position their products in a changing marketplace. To do this, a greater understanding of how consumers value sustainability in dairy products and the key attributes that contribute to the perception of sustainability are needed. The objective of this study was to characterize consumer perception of the sustainability of milk and dried dairy ingredients and their respective plant-based alternatives. To meet this objective, we conducted focus groups and 2 online surveys containing MaxDiff and check-all-that-apply (CATA) exercises.

\section{MATERIALS AND METHODS}

All focus group and survey procedures were conducted in compliance with North Carolina State University Institutional Review Board regulations. A graphical outline of the study can be found in Figure 1.

\section{Focus Groups}

Three 2-h focus groups with dairy consumers were conducted to establish parameters for consumer insights $(\mathrm{n}=23)$. Focus group consumers (10 women, 13 men; 25-64 yr of age; primary shoppers) were recruited from a database of $>11,000$ US consumers managed by the Sensory Service Center (North Carolina State University, Raleigh) using an online questionnaire. Respondents were asked to rate the importance of food sustainability on a 0 to 100 scale, as well as their knowledge about sustainability and agreement on a 5 -pt scale to statements about sustainability. $k$-Means clustering was used to segment consumers into 3 clusters (high, moderate, and low sustainability importance) from which participants were selected at random.

Prior to each focus group, consumers were provided a login to Pinterest.com, an online pinboard creation website. Consumers were asked to pin images, text, or links related to sustainability (in general), sustainable foods, sustainability (dairy product specific), examples of sustainable dairy products, and examples of nonsustainable dairy products. Each consumer was given a printout of their online pinboard at the start of the focus group. Aggregated pinboards with pinned images from all consumers were used as a discussion starter during the focus group.

During the focus group, 2 moderators facilitated discussion through the use of a moderator guide (Appendix). As an exercise, participants were given a stack of 30 sticky notes with terms related to sustainability on them. Terms were taken from sustainability-related claims on fluid milk packages found in a survey of grocery stores around the Raleigh/Durham, North Carolina area (Appendix). Participants were asked to categorize each sticky note by sticking it on a wall under one of the following labels: "required for sustainability," "contributes to but not required for sustainability," "misleading," and "I don't understand/am not familiar with this term." Consumers had the option to ignore and not categorize terms if they felt they were irrelevant. Term categorizations were used as a discussion starter for the remainder of the focus group. Audio and video were recorded for subsequent reference. Notes were taken by an observer remotely through a video feed to minimize distractions to panelists. Upon completion of the focus group, panelists were compensated with a gift card for their participation.

\begin{tabular}{|c|c|c|}
\hline Focus Groups & Online Survey \#1 & Online Survey \#2 \\
\hline $\begin{array}{l}\text { - Online pinboard } \\
\text { activity } \\
\text { - Term sorting activity }\end{array}$ & $\begin{array}{l}\text { Demographics and } \\
\text { psychographics } \\
\text { - MaxDiff w/ } 27 \text { attributes for } \\
\text { dairy product sustainability } \\
\text { - Categorization exercise: } \\
\text { sustainable/not sustainable } \\
\text { for commercially available } \\
\text { fluid milk and protein } \\
\text { powder products }\end{array}$ & $\begin{array}{l}\text { Demographics and } \\
\text { psychographics } \\
\text { - MaxDiff w/ } 27 \text { attributes for } \\
\text { dairy product sustainability } \\
\text { CATA Exercises w/ terms } \\
\text { sustainable, natural, healthy, } \\
\text { trustworthy, and ethical } \\
\text { - Generic Dairy Products } \\
\text { - Dried Ingredient Mockups }\end{array}$ \\
\hline
\end{tabular}

Figure 1. Graphical outline of study design. CATA = check all that apply; MaxDiff = maximum difference. 


\section{First Online Survey}

To assess how consumer perception of sustainability differed for dairy products and PBDA, focus group responses were used to develop an online survey with self-reported dairy (dairy-only consumers) or dairy + PBDA consumers (combination consumers). The survey was developed and launched using SSI Web (Lighthouse Studio version 9.6.1, Sawtooth Software, Orem, UT). The survey link was sent to a database of $>11,000$ US consumers managed by the Sensory Service Center (North Carolina State University, Raleigh). Only participants over $18 \mathrm{yr}$ of age were able to enter the survey.

Consumers were asked demographic and attitude questions including importance of sustainability, knowledge of sustainability, and knowledge of the dairy industry. Sustainability importance was rated on an unstructured line scale anchored with "not at all important" on one end and "extremely important" on the other end. Knowledge of food sustainability and knowledge of the dairy industry/dairy processing questions were rated on a 5-point scale from "not knowledgeable" to "extremely knowledgeable." Consumers were asked 10 agreement questions regarding sustainable food purchase on a 5-point scale from "disagree strongly" to "agree strongly."

Next, maximum difference (MaxDiff) scaling was used to rank the importance of 27 specific attributes of dairy products that affect sustainability (Table 1). These attributes were selected based on focus group results, the Food and Agriculture Organization of the United Nations (FAO) publication on sustainable food systems, and label claims and marketing material from dairy products currently available in grocery stores around Raleigh, North Carolina (FAO, 2014). The MaxDiff exercise was designed as 15 sets of bestworst questions, with 6 randomly displayed attributes per set. Each respondent was asked to select the attributes out of each set which were "most important" and "least important" to the sustainability of dairy products. Each participant saw each attribute at least 3 times.

Table 1. Mean maximum difference scaling scores ${ }^{1}$ for sustainability of dairy products $\left(\mathrm{n}=608 \text { dairy product } \text { consumers }^{2} \text {; first survey }\right)^{3}$

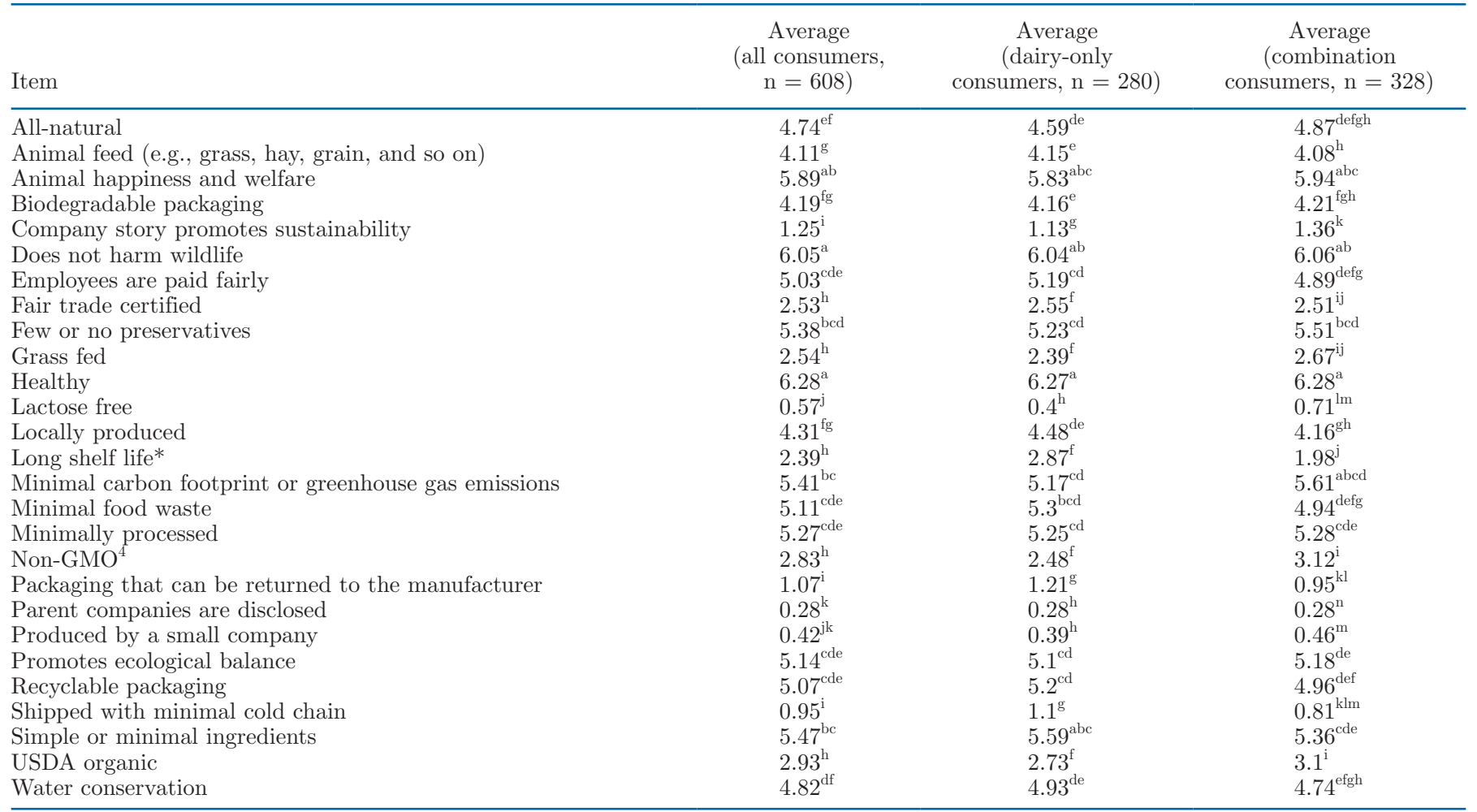

${ }^{\mathrm{a}-\mathrm{n}}$ Items within a column that do not share a superscript are significantly different $(P<0.05)$.

${ }^{1} \mathrm{~A}$ higher score indicates the attribute was perceived as more important to dairy product sustainability than an attribute with a lower score.

${ }^{2}$ Dairy product consumers are segmented into combination consumers (those who purchased both dairy products and plant-based dairy alternatives) and dairy-only consumers (those who purchased dairy products but not plant-based dairy alternatives).

${ }^{3} \mathrm{Sum}$ of values in each column is 100 total points, and the results are interpreted as ratio-scaled values.

${ }^{4} \mathrm{GMO}=$ genetically modified organism.

*Items followed by a asterisk indicate that the averages for dairy-only and combination consumers are statistically different $(P<0.05)$. 
Finally, consumers were shown photos of dairy and plant-based fluid milk and dried ingredients and asked to classify each photo as sustainable or nonsustainable. All photos used represented products currently available on the market or realistic product prototypes. Prototypes were created using Adobe Photoshop CC 2018 version 19.0 20170929.r.165 2017/09/29: 1138933 x64 (Adobe Inc., San Jose, CA). Product photos were categorized using the following attributes that were selected to mimic variation between products currently on the market. For fluid milks, source (animal, plant, nut, coconut, animal-free), packaging (plastic, carton, can, glass), genetically modified organism (GMO) status (GMO and non-GMO), organic status (organic, conventional), and serving size (single-serve, multiserve) were evaluated. For powders, source (animal, nut, plant) and packaging (plastic container, pouch) were evaluated. Respondents were shown 50 photos in total. For fluid milks, respondents were shown a random subset of 25 out of 63 photos. For powders, all respondents evaluated the same 24 photos. The product presented first (milks or powders) was randomized as well as the presentation of the photos within each product set.

\section{Second Online Survey}

To further evaluate consumer perception of sustainability as it pertained to dried dairy ingredients, and to determine if consumers perceived differences in sustainability among different dried dairy ingredients, an online survey with self-reported dairy consumers was designed based on responses to the first survey and focus groups. The survey was developed and launched using SSI Web Lighthouse Studio. The survey link was sent to a database of $>11,000$ US consumers managed by the Sensory Service Center (North Carolina State University, Raleigh). Only participants over 18 years of age were able to enter the survey. The second online survey was conducted 3 mo after the first online survey closed. Participants from the first survey could participate in the second survey.
First, consumers were asked the same demographic and attitude questions from the first survey (including importance of sustainability, knowledge of sustainability, and knowledge of the dairy industry), using the same scales. Consumers then evaluated generic, unbranded photos of 10 common dairy products (fluid milk, yogurt, butter, sour cream, coffee creamer, whipped cream, cottage cheese, ice cream, cheese, and protein powder). Consumers were asked to check any attributes they believed to apply to the product in the photo from a list of 6 attributes in a CATA format (sustainable, natural, healthy, trustworthy, ethical, and none).

Finally, consumers who indicated they were familiar with at least one dried dairy ingredient repeated the categorization exercise with photos of dried dairy ingredients. Consumers who indicated they were not familiar with any dried dairy ingredients did not complete this exercise. Respondents were shown a partial presentation of 32 out of 96 product photos. All photos used represented products currently available on the market or realistic product prototypes created using Adobe Photoshop CC 2018 (Figure 2). The following attributes were investigated in a factorial design: ingredient type [skim milk powder (SMP), whey protein concentrate (WPC), whey protein isolate (WPI), casein, micellar casein concentrate (MCC), and milk protein concentrate (MPC)], package type (pouch and tub), organic status (organic and conventional), and feed type (grass-fed and non-grass-fed).

\section{Data Analysis}

All statistical analyses were conducted with XLSTAT version 2019.2.1 (Addinsoft, Paris, France), with the exception of mixed model logistic regression to analyze photo categorization data (for both surveys) performed in SAS version 9.4 (SAS Institute, Cary, NC), MaxDiff score determination (for survey 1 ) via hierarchical Bayesian regression using Lighthouse Studio, and statistical comparison of MaxDiff scores between consumer
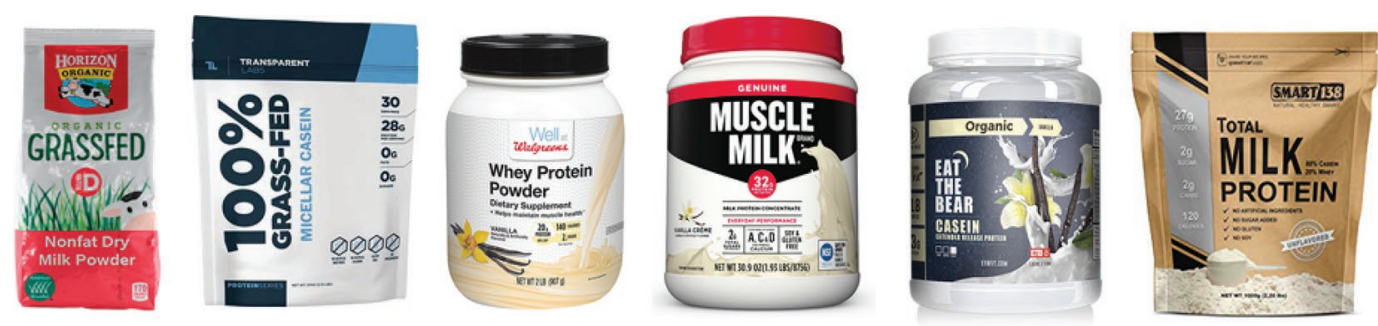

Figure 2. Examples of market-realistic product photos generated for use in the second online survey. 
groups, which was performed in the Sawtooth MaxDiff Online Analyzer (accessed 11.5.2019, Sawtooth Software, Sequim, WA). All analyses were performed at $95 \%$ confidence $(P<0.05)$.

Sustainability importance in the focus group screener and both subsequent surveys was considered a continuous variable, with "not at all important" scored as a 0 and "extremely important" scored as a 100. Agglomerative hierarchical clustering on sustainability importance and agreement questions was used to determine the number of clusters, then $k$-means clustering was used to segment consumers into clusters for focus group participant recruitment. Note-based analysis from focus groups was used to identify key points. To reduce personal bias, consumer responses were discussed and compiled by both moderators and the observer. Key points mentioned by two-thirds or more of participants in all focus groups were used for development of questions for the subsequent online surveys.

Survey results were analyzed via univariate and multivariate statistics. Five-point scale agreement questions were analyzed with Kruskal-Wallis one-way ANOVA with Dunn's nonparametric multiple pairwise comparisons. Kruskal-Wallis one-way ANOVA with Dunn's nonparametric multiple pairwise comparisons was used to determine if ordinal demographic questions differed between groups of consumers, and chi-squared analysis was used to determine if nominal demographic questions differed between groups of consumers. Frequencies of responses to CATA questions were analyzed using chi-squared analysis. Mixed model logistic regression was performed to determine how product photo attributes related to the likelihood of a product being considered sustainable, natural, trustworthy, or ethical. Respondent number was considered a random effect in this analysis.

\section{RESULTS}

For clarity, consumers who reported that they purchased only dairy products are referred to as dairy-only consumers, whereas those who reported that they purchased both dairy products and PBDA are referred to as combination consumers.

\section{Focus Groups}

Consumers perceived differences in sustainability between product categories (e.g., milk vs. yogurt) and made judgments about sustainability largely from looking at product packaging before purchase. Key attributes for sustainability from focus groups were packaging, environmental impacts, animal welfare, and simple ingredient lists.
Most consumers agreed that the food industry (including the dairy industry) should exercise more transparency when providing sustainability information to consumers. Many sustainability terms, such as resource cycling and ecological balance, were not well understood by consumers, who expressed that they were more likely to ignore or distrust sustainability claims that they do not understand. Most consumers (approximately 60\%) struggled to define common terms such as organic, non-GMO, and animal welfare, expressing that while they frequently heard these terms, they did not understand their implications fully. Although consumers desired greater transparency from companies, they did not always trust or understand information currently provided by companies. These results demonstrate a need for genuine, easily understandable sustainability messaging from industry to consumers, including on product packaging.

\section{First Online Survey}

Survey Demographics. A total of 608 consumers (280 dairy-only consumers and 328 combination consumers) participated in the survey. Of the 608 respondents, $23.7 \%$ were male and $76.3 \%$ were female. The majority of participants identified as Caucasian (75.8\%), followed by Black/African American (10.2\%), South Asian or Indian (5.1\%), Latino or Hispanic (4.4\%), and East Asian (4.6\%). An even distribution of ages was reported: $15.1 \%$ of the participants were 18 to 24 yr, $24.5 \%$ were 25 to 34 yr, $18.9 \%$ were 35 to $44 \mathrm{yr}, 17.9 \%$ were 45 to $54 \mathrm{yr}, 13.5 \%$ were 55 to $64 \mathrm{yr}$, and $10.0 \%$ were $64 \mathrm{yr}$ or older. A range of total annual household incomes was also self-reported $(<\$ 19,999$ to $>\$ 100,000)$.

Purchase Habit and Agreement Questions. The average self-reported importance of sustainability was 68.6 (out of 100). The average sustainability importance score for dairy-only consumers was $64.8(\mathrm{SD}=22.9)$, whereas the average score for combination consumers was significantly higher at $71.9(\mathrm{SD}=20.0)(P<0.05)$. Sex and income did not differ between dairy-only and combination consumers $(P>0.05)$. However, the age of the combination consumers was lower than that of the dairy-only consumers $(P<0.05)$. Fifty-one percent of consumers indicated that they looked for information about the sustainability of foods. Among those consumers who did look for information, the most frequently cited information source was product labels $(82.3 \%$; consistent with focus groups), followed by websites not affiliated with food companies (49.2\%), company websites $(48.9 \%)$, word of mouth $(45.3 \%)$, newspapers or magazines $(43.7 \%)$, government websites $(36.7 \%)$, blogs $(28.3 \%)$, friends on social media $(28.8 \%)$, social 
media profiles from organizations not affiliated with food companies $(24.1 \%)$, company social media profiles (19.90\%), and email newsletters (18.6\%).

Seventy-seven percent of respondents agreed that they believed food sustainability should be promoted for the greater good, rather than personal benefit. Fifty-five percent were willing to pay more for sustainable foods, $34.49 \%$ agreed they always considered sustainability when purchasing foods and beverages, and $26.0 \%$ avoided purchase of foods or beverages that were not sustainable. The most frequently agreed with reason for purchase of sustainable foods among all consumers was "for the greater good" $(77.5 \%)$, followed by for the wellbeing of the planet $(61.2 \%)$, the economic wellbeing of others $(53.0 \%)$, because they are better/safer (48.0\%), and because they offer a better experience than nonsustainable products (37.2\%). A lower percentage of dairy-only consumers agreed they purchased sustainable products for each reason than combination consumers $(P<0.05$; Figure 3$)$. Approximately half of consumers considered themselves moderately or somewhat knowledgeable about both sustainability of foods and the dairy industry $(57.6 \%$ and $45.2 \%$, respectively). Self-reported knowledge of sustainability and knowledge of the dairy industry were higher for combination consumers than dairy-only consumers $(P<0.05)$.

MaxDiff Scaling. The MaxDiff scaling results are shown in Table 1. Healthiness was the most important attribute for sustainability $(P<0.05)$. The next most important attributes were minimal carbon footprint/ greenhouse gas emissions, few/no preservatives, animal happiness and welfare, and simple/minimal ingredients. These 5 most important attributes aligned with focus group results. The least important attributes were parent companies are disclosed, produced by a small company, lactose free, shipped with minimal cold chain, and packaging that can be returned to the manufacturer. The low importance placed by consumers on minimal cold chain (along with a relatively high importance placed on "locally produced") indicates differences in how consumers and industry perceive sustainability, and perhaps a lack of knowledge regarding production and shipping methods. MaxDiff scaling results were similar between dairy-only consumers and combination consumers, suggesting these consumers share similar definitions of sustainable dairy products.

CATA Exercise. Source (plant, nut, coconut, animal-free, or animal), package (glass, carton, can, or plastic), organic status (organic or conventional), and package size (single-serve or multi-serve; $P<0.05$ ), but not GMO status (GMO or non-GMO) affected consumer perceived sustainability of fluid milks and milk alternatives $(P>0.05)$. Plant-based, animal-free, nut-based, and coconut-based fluid milk alternatives were more likely to be marked as sustainable than fluid cow milk $(P<0.05)$. Plant-based alternatives were also more likely to be considered sustainable than nut-based and coconut-based alternatives $(P<0.05)$. Animal-free cow milk alternatives (products produced by genetically engineered microorganisms) were at parity with the plant-based, nut-based, and coconut-based alternatives for sustainability. However, as these products are uncommon in the market at the time of this study, only

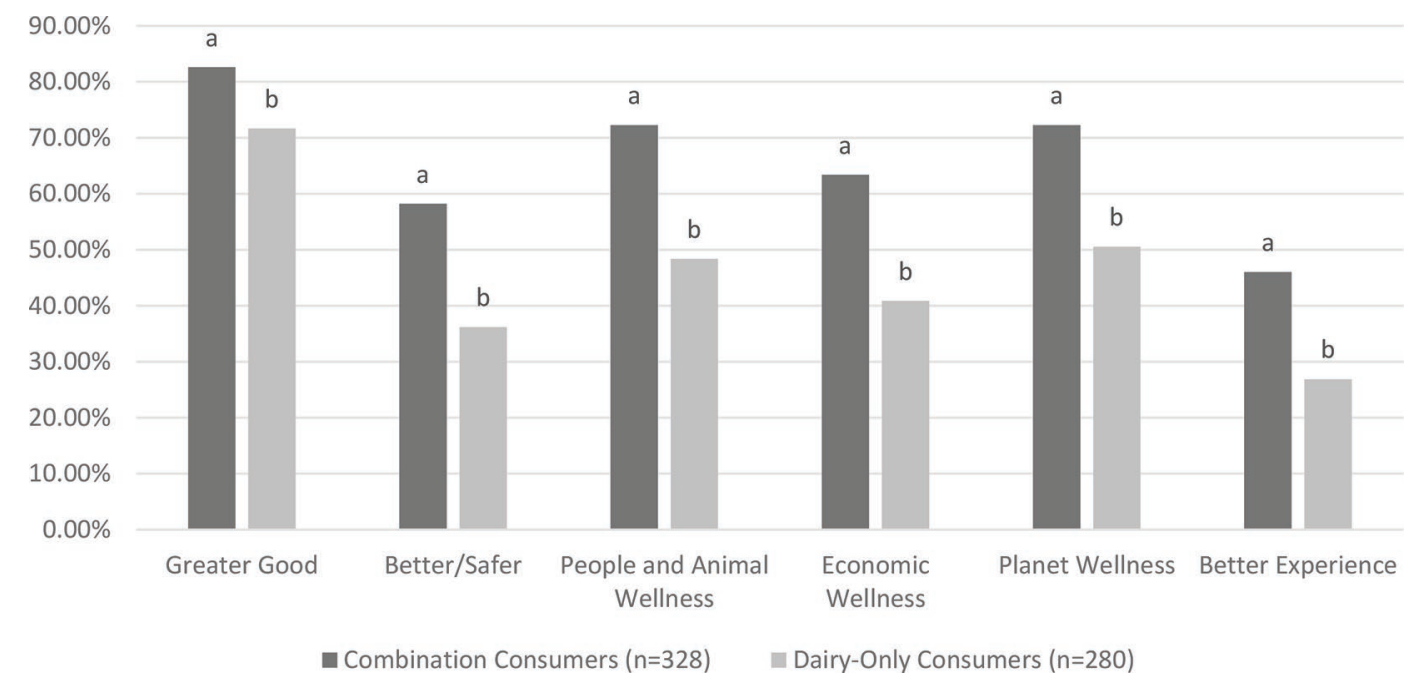

Figure 3. Percentage of consumers who agreed that they purchased sustainable foods for each reason (first survey). $\mathrm{n}=608$ dairy product consumers. Dairy product consumers are segmented into combination consumers (those who purchased both dairy products and plant-based dairy alternatives) and dairy-only consumers (those who purchased dairy products but not plant-based dairy alternatives). Different letters (a,b) within attributes indicate significant differences between consumer segments $(P<0.05)$. 
2 animal-free products were included in this CATA exercise, and these results should be interpreted with caution.

Milks and milk alternatives packaged in glass were considered the most sustainable, followed by those packaged in cartons $(P<0.05)$. Products packaged in plastic were the least likely to be marked as sustainable $(P<0.05)$, while those packaged in cans scored at parity with both those packaged in cartons and those packaged in plastic. Organic products were more likely to be considered sustainable than conventional products $(P<0.05)$, and multi-serve products were more likely to be considered sustainable than single-serve products $(P<0.05)$. There was no difference in the likelihood of being considered sustainable between GMO and non-GMO products $(P>0.05)$. For protein powders, source (plant, nut, or animal) and package (plastic tub or pouch) affected consumer perceived sustainability $(P<0.05)$. Plant-based powders were considered the most sustainable, followed by nut-based powders and then animal (dairy-based whey, milk powder, or MCC) powders, which were considered the least sustainable $(P<0.05)$. Powders packaged in pouches were more likely to be marked as sustainable than those packaged in plastic tubs $(P<0.05)$.

\section{Second Online Survey}

As for previous results, for clarity, consumers who reported they only purchased dairy products are referred to as dairy-only consumers while those who reported they purchased dairy products in addition to PBDA are referred to as combination consumers. A total of 777 consumers (369 dairy-only consumers and 408 combination consumers) participated in the survey. Of these consumers, $\mathrm{n}=689$ (310 dairy-only consumers and 379 combination consumers) indicated they were familiar with at least one dried dairy ingredient. Consumers who did not indicate they were familiar with at least one dried dairy ingredient were not included in the dried dairy ingredient categorization exercise.

Survey Demographics. Of the respondents, $34.0 \%$ were male and $66.0 \%$ were female. The majority of participants identified as Caucasian $(77.6 \%)$, followed by Black/African American (8.5\%), South Asian or Indian (7.5\%), Latino or Hispanic (4.8\%), and East Asian (4.6\%). An even distribution of ages was reported: $25.4 \%$ of the participants were 18 to $24 \mathrm{yr}, 28.8 \%$ were 25 to 34 yr, $19.0 \%$ were 35 to 44 yr, $13.0 \%$ were 45 to 54 yr, $10.3 \%$ were 55 to $64 \mathrm{yr}$, and $3.5 \%$ were 64 yr or older. An even distribution of total annual household incomes was also self-reported $(<\$ 19,999$ to $>\$ 100,000)$.

Purchase Habits and Agreement Questions. About $88 \%$ of respondents indicated they were familiar
Table 2. Consumer familiarity with dried dairy ingredients (second survey); $\mathrm{n}=777$ dairy product consumers ${ }^{1}$

\begin{tabular}{lrcc}
\hline Product (\%) & All & $\begin{array}{c}\text { Combination } \\
(\mathrm{n}=369)\end{array}$ & $\begin{array}{c}\text { Dairy only } \\
(\mathrm{n}=408)\end{array}$ \\
\hline Skim milk powder & 56.5 & $62.3^{\mathrm{a}}$ & $50.1^{\mathrm{b}}$ \\
Whey protein isolate & 43.6 & $52.9^{\mathrm{a}}$ & $33.3^{\mathrm{b}}$ \\
Whey protein concentrate & 56.8 & $65.7^{\mathrm{a}}$ & $46.9^{\mathrm{b}}$ \\
Casein & 29.0 & $36.3^{\mathrm{a}}$ & $20.9^{\mathrm{b}}$ \\
Milk protein concentrate & 26.3 & $37.0^{\mathrm{a}}$ & $14.4^{\mathrm{b}}$ \\
Micellar casein concentrate & 7.9 & $11.5^{\mathrm{a}}$ & $3.8^{\mathrm{b}}$ \\
Blends & 44.5 & $54.4^{\mathrm{a}}$ & $33.6^{\mathrm{b}}$ \\
Other & 1.8 & $1.0^{\mathrm{b}}$ & $2.7^{\mathrm{a}}$ \\
\hline
\end{tabular}

${ }^{a, b}$ Different superscripts in rows indicate a significant difference between combination and dairy-only consumers $(P<0.05)$.

${ }^{1}$ Percentages shown are the percentage of consumers who indicated they were familiar with each ingredient. Consumers were asked which products they were familiar with in a check-all-that-apply format. Dairy product consumers are segmented into combination consumers (those who purchased both dairy products and plant-based dairy alternatives) and dairy-only consumers (those who purchased dairy products but not plant-based dairy alternatives).

with at least one dried dairy ingredient. The majority of consumers were familiar with WPC (56.8\%) and SMP (56.5\%; Table 2). Consumers were least familiar with MCC (7.9\%; Table 2). Of the consumers who indicated that they purchased protein powders or dried dairy ingredients regularly $(\mathrm{n}=254$ overall, 189 combination consumers and 65 dairy-only consumers), the most commonly purchased dried dairy ingredients were WPC $(60.2 \%)$, WPI $(52.8 \%)$, and protein powder blends (50.0\%; Table 3$)$. The least commonly purchased ingredient was MCC (10.6\%).

Sex, age, and income did not differ between dairyonly and combination consumers $(P>0.05)$. Unlike for the first survey, we did not find differences in age between the 2 groups $(P>0.05)$. Agreement question results were similar to those from the first survey $(P$ $>0.05)$. Combination consumers were more likely to

Table 3. Consumer purchase habits for dried dairy ingredients (second survey); $\mathrm{n}=254$ dried dairy ingredient consumers $^{1}$

\begin{tabular}{ll}
\hline Product (\%) & All \\
\hline Whey protein concentrate & 60.2 \\
Whey protein isolate & 52.8 \\
Blends & 50.0 \\
Skim milk powder & 26.8 \\
Milk protein concentrate & 24.8 \\
Casein & 17.7 \\
Micellar casein concentrate & 10.6 \\
Other & 2.0
\end{tabular}

${ }^{1}$ Percentages shown are the percentage of consumers who self-reported they regularly purchased each ingredient. Consumers were asked which products they purchased regularly in a check-all-that-apply format. The dried dairy ingredient purchase habits question was only asked of consumers who indicated they purchased protein powders or dried dairy ingredients regularly in previous check-all-that-apply results with general products $(\mathrm{n}=254)$. 


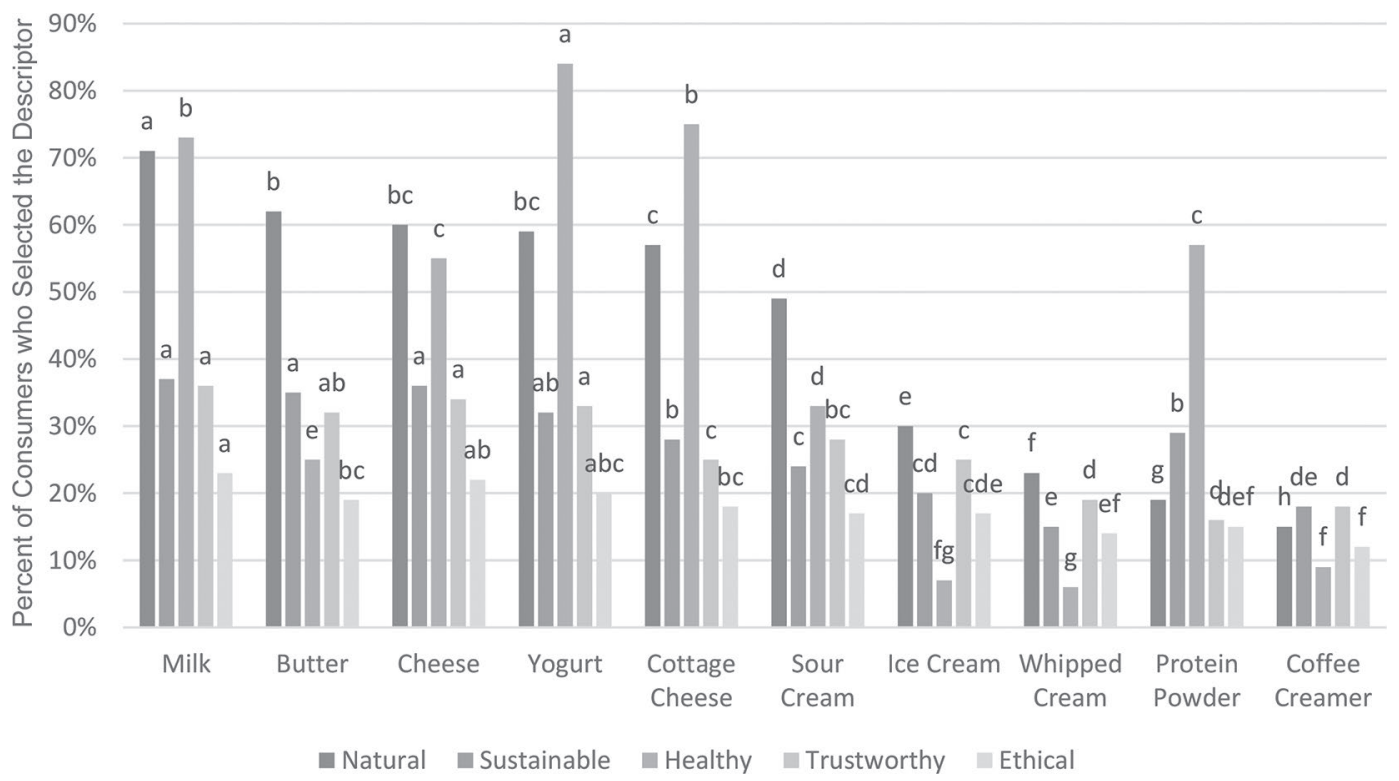

Figure 4. Generic dairy product check-all-that-apply results by product for the attributes sustainable, natural, healthy, trustworthy, and ethical (second survey). $\mathrm{n}=777$ dairy product consumers. Different letters $(\mathrm{a}-\mathrm{h})$ within products indicate significant $(P<0.05)$ differences between products among attributes.

report they looked for information about the sustainability of foods than dairy-only consumers $(67.4 \%$ vs. $38.8 \% ; P<0.05)$. The 3 most commonly cited sources of information regarding sustainability for all consumers were product labels (78.0\%), websites not affiliated with food companies or the government $(54.1 \%)$, and word of mouth $(50.2 \%)$. These results are similar to those of the first survey. The average self-reported importance of sustainability was 69.2 (out of 100). The average sustainability importance score for dairy-only consumers was $64.1(\mathrm{SD}=22.3)$, whereas the average score for combination consumers was higher 73.8 (SD $=20.2 ; P<0.05)$, consistent with survey 1 . Age, but not sex or income, affected sustainability importance, with average self-reported sustainability importance decreasing as age increased $(P=0.025)$.

Generic Dairy Product CATA Exercise. Consumers perceived differences in the sustainability, naturalness, healthfulness, ethicalness, and trustworthiness of different dairy products $(P<0.05)$. The percentage of consumers who selected a descriptor for each product ranged from 6 to $84 \%$ ( $\pm 19 \%$; Figure 4$)$. Combination consumers were more likely to check any product as sustainable, natural, healthy, trustworthy, and ethical than dairy-only consumers $(P<0.05)$. Healthy was the attribute with the greatest difference between the products for which the highest and lowest percentages of consumers checked the attribute ( $7 \%$ for whipped cream vs. $84 \%$ for yogurt; Figure 4). Conversely, the ethical attribute had the least difference between the products for which the highest and lowest percentages of consumers checked the attribute ( $12 \%$ for coffee creamer vs. $23 \%$ for milk; Figure 4). Milk was considered the most natural product $(P<0.05)$ and was among the products checked most frequently for sustainable, ethical, and trustworthy. However, yogurt was considered more healthy than milk $(P<0.05$; Figure 4). Healthy, sustainable, ethical, natural, and trustworthy loaded similarly (along the same factor in the same direction) on a principal component analysis biplot of the frequencies of term selection from this generic dairy CATA (Figure 5). This result further indicates there is significant overlap in consumer use of these terms.

Consumers tended to use the attributes healthy, natural, and sustainable with higher frequency than the terms ethical and trustworthy. Although this result could indicate they do not view dairy products as ethical or trustworthy, it is also possible that consumers are simply less accustomed to using these terms to describe food products. Our survey did not ask consumers to decide whether each product was ethical/trustworthy versus unethical/untrustworthy; instead, it asked them to select which of the 5 attributes they believed applied to the product. This allowed us to determine which attributes come to mind more easily when it comes to dairy products; however, a follow-up survey in which consumers are asked to choose between the positive and negative form of each attribute may provide additional insights as to whether consumers truly believe dairy products are not trustworthy or ethical. A biplot of 


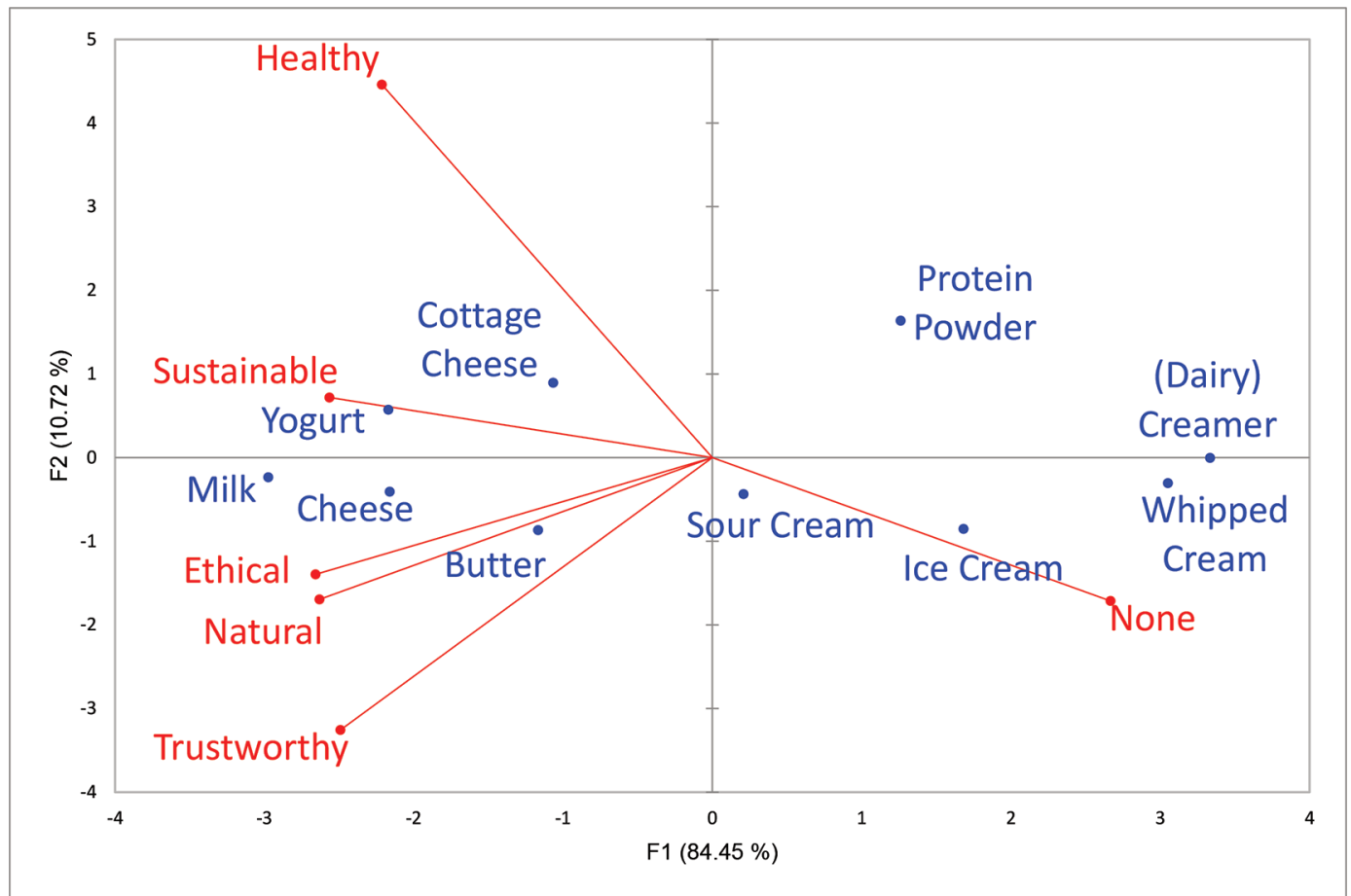

Figure 5. Principal component analysis biplot of frequencies of term selection from the generic dairy check-all-that-apply exercise for the attributes sustainable, natural, healthy, ethical, and trustworthy (second survey). $\mathrm{n}=777$ dairy product consumers. F1 and F2 represent principal components 1 and 2. Principal components are linear combinations of variables generated by principal component analysis, a dimension reduction method for multivariate data. Percentages show the percent of variability in the data explained by each principal component.

frequencies of term selection displayed 2 groupings of products (Figure 5). Protein powder, dairy creamer, whipped cream, and ice cream were characterized by a high frequency of selection of the term "none," with low frequency of selection of all other terms. By contrast, cottage cheese, yogurt, milk, cheese, and butter were characterized by low frequency of selection of the "none" term. Sour cream fell in between these groups on the biplot. This further reinforces the halo effect of term selection as these generic dairy products were rarely characterized by a single attribute. Respondents either used multiple terms to describe a product or none at all. One exception to this was protein powder. More than $50 \%$ of respondents indicated it was healthy, but few indicated it was sustainable, natural, trustworthy, or ethical. This discrepancy could be due to consumer association between protein powders and health/fitness in combination with consumer unfamiliarity with how protein powders are processed and produced.

Dried Ingredient CATA Exercise. Combination consumers were more likely to mark a dried dairy ingredient product as sustainable, natural, trustworthy, healthy, and ethical than dairy-only consumers $(P<$ 0.05 ). Dried ingredients labeled as organic and grass-fed were more likely to be marked as sustainable, natural, healthy, ethical, and trustworthy than conventional and non-grass-fed products $(P<0.05)$. Dried ingredients packaged in a pouch were more likely to be marked as sustainable, natural, healthy, ethical, and trustworthy than dried ingredients packaged in a tub $(P<0.05)$.

Ingredient type significantly affected likelihood of a product being checked as all 5 attributes $(P<0.05)$ (Figure 6). Consumers used the terms sustainable, natural, and healthy with greater frequency than the terms ethical and trustworthy, suggesting once again that consumers may not fully understand these terms or be comfortable using them in relation to dairy products. The WPC and SMP were the most likely ingredients to be marked sustainable, whereas MCC was the least likely to be marked sustainable $(P<$ $0.05)$. The WPI scored at parity with SMP, WPC, and casein $(P>0.05)$. Casein was less likely to be marked sustainable than SMP or WPC $(P<0.05)$. The MPC, which scored at parity with casein, was less likely to be marked sustainable than WPI but more likely to be marked sustainable than MCC $(P<0.05)$. Casein scored at parity with both MPC and SMP/WPI $(P$ $>0.05)$. The WPC was the most likely to be marked healthy, followed by WPI $(P<0.05)$. The MCC was the least likely to be marked healthy $(P<0.05)$. Casein and SMP (which scored at parity, $P>0.05$ ) were more likely to be marked healthy than MCC but less likely 


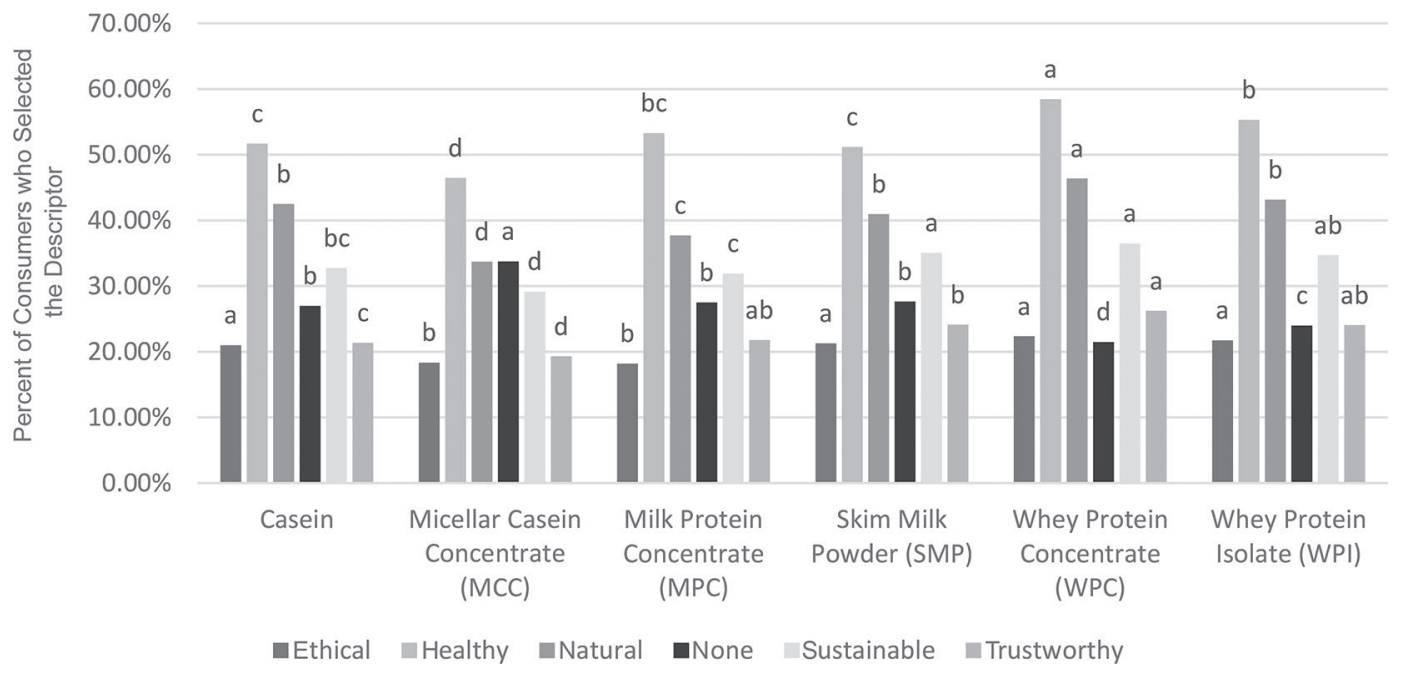

Figure 6. Dried ingredients check-all-that-apply results by product for the attributes sustainable, natural, healthy, trustworthy, and ethical (second survey). $\mathrm{n}=689$ consumers familiar with at least one dried dairy ingredient. Different letters (a-d) within attributes indicate significant $(P<0.05)$ differences among products within specific attributes.

than WPI $(P<0.05)$. The MPC scored at parity with both WPI and casein/SMP $(P>0.05)$. The WPC was the most likely ingredient to be marked natural, followed by WPI, SMP, and casein (which scored at parity), then MPC, then MCC, which was the least likely to be marked as natural $(P<0.05)$. The WPC was the most likely ingredient to be marked trustworthy, along with MPC and WPI, which scored at parity with each other and WPC, as well as with SMP which was less likely to be marked trustworthy than WPC $(P<$ 0.05 ). Casein was less likely than all other attributes to be marked as trustworthy with the exception of MCC, which was the least likely $(P<0.05)$.

As respondents in this exercise were asked to check whether an attribute applied to a product (rather than choose between a binary positive and negative option, e.g., sustainable/not sustainable), it is possible that differences in frequencies of attribute selection could be due to lack of familiarity with certain protein products. For example, MCC, which was among the least likely to be marked as all attributes, was familiar to just $7.9 \%$ of respondents. The MCC is a relatively new dried dairy protein ingredient and, as such, is not as widely commercially available. By contrast, WPC, which was among the most likely to be marked as all attributes, was familiar to $56.8 \%$ of respondents. It is possible that educating consumers about the production of dried dairy ingredients would increase consumer perception of these products as sustainable, natural, healthy, trustworthy, and ethical. One limitation of this study is that we cannot fully determine if consumers who did not check a product as sustainable truly felt the product was unsustainable, versus having a neutral opinion or being too uninformed or unfamiliar with the product to answer the question. Knowing this, we selected this design because we aimed to improve data quality and reduce nonresponse bias from respondent drop out. In consumer surveys, item nonresponse (the behavior of respondents who complete the entire survey but do not answer particular questions) increases when questions are too complex or difficult for the respondent to answer easily (Rässler and Riphahn, 2006). If consumers are asked a large number of forced-answer questions they are unable to answer, their chances of abandoning the survey increase greatly (Décieux et al., 2015). As such, we believe the percentages of term selection for each product realistically represent the estimated percentage of the population who are both familiar enough with the product to form an opinion and who believe the term applies to the product.

\section{DISCUSSION}

Consumers reported a moderately high level of importance placed on the sustainability of dairy foods, but our results also indicate that consumers have difficulty fully understanding the concept and may thus have difficulty choosing sustainable products even if they are motivated to make sustainable choices. This is consistent with previous studies (Verain et al., 2012; Grunert et al., 2014; Sautron et al., 2015). Focus group and first survey MaxDiff results identified 5 key attributes for sustainability: minimal carbon footprint/ greenhouse gas emissions, few/no preservatives, animal 
happiness and welfare, and simple/minimal ingredients. These attributes reference all 3 types of sustainable development strategies outlined by the United Nations (economic/profit, social/people, and environmental/ planet); however, focus group results indicated it is unlikely that the average dairy consumer has a clearly defined perception of sustainability (United Nations Department of Economic and Social Affairs, 2015). Factors we found important for sustainability were also found to be important for the purchase of organic milk by Harwood and Drake (2018), which were enhanced nutrition/wellbeing, environmental sustainability, ethical animal treatment, and local farm support. These similarities further suggest that dairy consumers' concept of sustainability and other altruistic purchase motivations are deeply intertwined with their concepts of other related terms. Consumers in focus groups indicated that they made sustainability judgments about dairy products largely by reading product labels at point of purchase, although many also indicated they did not fully understand sustainability- and ethicsrelated packaging claims. These consumers may be driven by the feeling they perceive after seeing sustainability messaging on dairy packaging rather than by forming opinions through prior research. These results are consistent with previous findings on organic milk by Harwood and Drake (2018), who found extrinsic milk features that imply passive participation in altruistic movements (such as sustainability, animal welfare, and so on) were drivers of value for some dairy consumers who viewed organic milk purchase as a "passively benevolent" act.

Our first survey CATA results suggested that consumers perceived dairy products as less sustainable than PBDA because dairy-based fluid milks and protein powders were less likely to be sustainable than plant or nut alternatives even when controlling for package type or organic status. Accordingly, consumers who purchased both PBDA and dairy products (the combination consumers) placed a higher self-reported importance on sustainability than those who purchased dairy products only (dairy-only consumers). Combination consumers were significantly more involved with sustainability than dairy-only consumers, and were both more likely to look for information about the sustainability of foods and to agree that they purchased sustainable foods for every reason we provided than dairy-only consumers. Despite regular self-reported purchase of PBDA, these combination consumers were also more likely to purchase and be familiar with all dried dairy ingredients than the dairy-only consumers. These results suggest that combination consumers are more informed about food and food labeling than dairy-only consumers, and sustainability-related marketing efforts should take this observation into account. Further research is needed to understand the differing needs and expectations of dairy foods between combination and dairy-only consumers. McCarthy et al. (2017) observed a unique value ladder for nondairy plant-based beverage and combination consumers in means-end-chain interviews in which the plant-based attribute of nondairy beverages led to peace of mind and relief of stress regarding animal mistreatment and environmental impacts. Consumers of dairy milk exclusively in this previous study did not demonstrate any value ladders related to sustainability, perhaps indicating that they are less involved with sustainability relative to combination/exclusively nondairy milk consumers.

Food choice inherently involves trade-offs between varying motives, which for the purpose of investigating sustainable food consumption can be grouped into "proself" and "altruistic" motives (van Dam and van Trijp, 2011; Aschemann-Witzel, 2015). High price is often considered a trade-off of sustainable products, but flavor or product quality trade-offs have also been suggested as a deterrent for consumer purchase of sustainable foods (Grunert et al., 2014; Aschemann-Witzel, 2015). Our results suggest that consumers are more likely to agree that they purchased sustainable products for reasons focused on others (the greater good, the wellness of people and animals, and the wellness of the planet) rather than reasons focused on themselves (a better experience or better/safer products). At the same time, few consumers disagreed that sustainable products offered a better experience, with $>40 \%$ of consumers in both surveys responding they neither agreed nor disagreed with this statement. However, previous work on organic milk consumers suggested an opposite effect. Although organic status of a product is not the same as its sustainability, organic status is another example of an ethical/altruistic product attribute (one that may overlap with consumer perception of sustainability). Previous study results indicated that not only do these consumers not see an unavoidable trade-off between organic status and milk quality, they believed organic milk was of higher quality and had better flavor than conventional milk (Harwood and Drake, 2018). Similarly, consumer perceived liking and liking following tasting of both meat and cheese has been shown to increase for Italian consumers when consumers were told the product was organic or promoted animal welfare (Napolitano et al., 2010). Further research is needed to fully understand perception of the trade-off between sustainability/ethics and product quality in sustainable dairy foods and PBDA, if a significant one does exist for consumers. 
The results from both our online surveys indicated that more than half of dairy product consumers are actively looking for sustainability-related information. Although product labels are by far the most common source of sustainability information, many consumers are also turning to both company websites and websites not affiliated with companies or the government. Word of mouth is also a commonly cited sustainability information source for consumers. Social media profiles, both those associated and not associated with dairy foods companies, were among the least commonly cited sources of sustainability-related information. While a company story that promotes sustainability was not considered important in the MaxDiff analysis, it is likely that consumers are looking for consistency in sustainability messaging between product labels and company websites, especially in the face of consumer backlash against "greenwashing" and misrepresentation of sustainability efforts by companies on social media (Lyon and Montgomery, 2013; Toptal et al., 2019). Because packaging is the primary source of sustainability-related information, dairy producers seeking to emphasize the sustainability of their products should carefully consider how to present sustainability-related information in a clear, engaging, and accessible manner on product packaging. We noticed significant packaging effects in the CATA exercises in both our first and second surveys, as both fluid milks and dried ingredients packaged in glass or paper-based packaging were more likely to be considered sustainable than those packaged in plastic, and dried ingredients packaged in pouches were more likely to be considered sustainable than those packaged in tubs. Further research is needed to understand how consumers perceive different sustainability-related claims that may appear on packaging, as choosing the correct claim could mean the difference between a sustainability-conscious consumer purchasing a product, ignoring it completely, or writing off sustainability-related marketing as insincere.

Consumers perceived sustainability differences between dairy products and PBDA, between different generic dairy products, and between different specific dairy dried ingredients. Our second survey CATA exercise suggested that although the terms sustainable, natural, healthy, ethical, and trustworthy were used independently in relation to dairy foods, there was significant cognitive overlap between the terms, consistent with previous work (Schuldt et al., 2012; Sautron et al., 2015; Harwood and Drake, 2018). The MaxDiff results from our first online survey further reinforced this overlap, as healthy was considered the most important attribute for a sustainable dairy food, and 2 of the top 5 attributes from the MaxDiff were related to ethical treatment of animals ("animal happiness and welfare" and "doesn't harm wildlife"). Consumers used the terms natural and healthy more frequently in relation to all the dairy foods presented than sustainable, trustworthy, and ethical. Because there is considerable cognitive overlap between the terms sustainable, natural, and healthy, dairy producers should consider emphasizing perception of their products as natural and healthy, thus increasing sustainability perception as a halo effect. An example of this halo effect can be seen for the grass-fed products included in our second online survey CATA exercise. Although "USDA organic" scored of very low importance to sustainability in our MaxDiff exercise, organic dried ingredients in the CATA were significantly more likely to be considered sustainable, natural, healthy, trustworthy, and ethical than conventional dried ingredients $(P<0.05)$. Dried ingredients labeled grass-fed (the 10th most important attribute for sustainability from our MaxDiff) were significantly more likely to be considered sustainable, natural, healthy, trustworthy, and ethical than those not labeled grass-fed $(P<0.05)$. As grass-fed and the idea of cows grazing freely is associated with animal welfare (and thus ethical treatment of animals), the inclusion of grass-fed as a label claim could increase consumer perception of multiple positive attributes (Ellis et al., 2009; Napolitano et al., 2010). This is consistent with previous research with German consumers that demonstrated a pasture-raised attribute increased consumer willingness to pay for milk due to greater positive perception of animal welfare (Markova-Nenova and Wätzold, 2018).

Familiarity and consumer knowledge also appear to contribute to sustainability perception. Whey protein concentrate, which was among the most likely dried dairy ingredients to be considered sustainable, natural, healthy, trustworthy, and ethical, was the dried dairy ingredient that the most consumers indicated they were familiar with $(56.8 \%)$. By contrast, MCC, which was the dried dairy ingredient that the least number of consumers indicated they were familiar with, was among the least likely to be considered sustainable, natural, healthy, trustworthy, and ethical. This result suggests that educating consumers about dried dairy ingredient processing may increase the likelihood they perceive these products as sustainable, natural, healthy, trustworthy, or ethical.

\section{CONCLUSIONS}

Although dairy product and PBDA consumers selfreport relatively high levels of personal importance of sustainability, there is much confusion as to what the 
sustainability of dairy products actually involves. The top 5 most important attributes to dairy sustainability identified by this study were minimal carbon footprint/ greenhouse gas emissions, few/no preservatives, animal happiness and welfare, and simple/minimal ingredients. These attributes are different than the purely environmentally focused concept of sustainability typically adopted by industry, and suggest that consumer sustainability perception is muddled and overlapping with their perception of related terms. There is cognitive overlap among the terms sustainable, natural, healthy, ethical, and trustworthy as they relate to dairy products, but consumers do use the terms distinctly. Our results suggest a misalignment between consumer and industry definitions of sustainability, which if addressed could lead to development of marketing messaging that better appeals to consumers. Furthermore, we found consumer perception of sustainability differed widely among dairy products. Within the scope of this study, plant-based alternatives to fluid milk and protein powders were considered more sustainable than dairy products, but package type and organic status also played a significant role in consumer sustainability perception. Consumers perceived sustainability differences among the general categories of dairy products investigated in our study as well as among products in a specific dairy category (as demonstrated in this study with dried dairy ingredients). As consumer concern with sustainability grows, understanding these differences will offer an advantage to dairy product producers who must understand how to strategically position their products in a changing marketplace. As our results suggest consumers may be biased toward believing PBDA are more sustainable than their dairy counterparts, providing consumers with the necessary knowledge to make an alternative judgment is key. Dairy companies may be able to differentiate themselves by helping consumers make these choices by simplifying sustainability-related messaging as well as maintaining open, transparent communication regarding sustainability. Although more research is needed, educating consumers through multiple approaches (for example, optimizing product packaging, including information on product websites, and working with third-party websites to disseminate information) could be crucial to get sustainability messaging to stick when consumers make snap judgments at the point of purchase.

\section{ACKNOWLEDGMENTS}

Funding was provided in part by the National Dairy Council (Rosemont, IL), Dairy West (Meridian, ID), Milk Specialties Global (Eden Prairie, MN), and Land
O'Lakes (Arden Hills, MN). The use of trade names does not imply endorsement or lack of endorsement by those not mentioned. The authors have not stated any conflicts of interest.

\section{REFERENCES}

Aschemann-Witzel, J. 2015. Consumer perception and trends about health and sustainability: Trade-offs and synergies of two pivotal issues. Curr. Opin. Food Sci. 3:6-10. https://doi.org/10.1016/j .cofs.2014.08.002.

Baertlein, L. 2015. Starbucks' U.S. shops turn to coconuts as nondairy demand soars. Reuters Business News. Accessed Aug. 25, 2016. http://www.reuters.com/article/2015/02/04/us-starbucks -nondairy-idUSKBN0L82GR20150204.

Bernués, A., A. Olaizola, and K. Corcoran. 2003. Labeling information demanded by European consumers and relationships with purchasing motives, quality and safety of meat. Meat Sci. 65:1095-1106. https://doi.org/10.1016/S0309-1740(02)00327-3.

Crawford, E. 2020. Most consumers don't link diet \& climate, but sustainability marketing could boost plant-based sales. Accessed May 7, 2020. https://www.foodnavigator-usa.com/Article/2020/ 02/17/Most-consumers-don-t-link-diet-climate-but-sustainability -marketing-could-boost-plant-based-sales.

Décieux, J. P., A. Mergener, K. M. Neufang, and P. Sischka. 2015. Implementation of the forced answering option within online surveys: Do higher item response rates come at the expense of participation and answer quality? Psihologija (Beogr.) 48:311-326. https://doi .org/10.2298/PSI1504311D.

Ellis, K. A., K. Billington, B. McNeil, and D. E. F. McKeegan. 2009. Public opinion on UK milk marketing and dairy cow welfare. Anim. Welf. 18:267-282.

FAO. 2014. Developing sustainable food value chains: Guiding principles. Accessed Sep. 22, 2020. http://www.fao.org/3/a-i3953e.pdf.

Franklin-Wallis, O. 2019. White gold: The unstoppable rise of alternative milks. The Guardian. Accessed May 7, 2020. https://www .theguardian.com/news/2019/jan/29/white-gold-the-unstoppable -rise-of-alternative-milks-oat-soy-rice-coconut-plant.

Fuentes, C., and M. Fuentes. 2017. Making a market for alternatives: Marketing devices and the qualification of a vegan milk substitute. J. Mark. Manag. 33:529-555.

Grunert, K. G., S. Hieke, and J. Wills. 2014. Sustainability labels on food products. Consumer motivation, understanding, and use. Food Policy 44:177-189. https://doi.org/10.1016/j.foodpol.2013 .12 .001 .

Harwood, W. S., and M. A. Drake. 2018. Identification and characterization of fluid milk consumer groups. J. Dairy Sci. 101:8860-8874. https://doi.org/10.3168/jds.2018-14855.

Jo, Y., D. M. Benoist, A. Ameerally, and M. A. Drake. 2018. Sensory and chemical properties of Gouda cheese. J. Dairy Sci. 101:19671989. https://doi.org/10.3168/jds.2017-13637.

Lyon, T. P., and A. W. Montgomery. 2013. Tweetjacked: The impact of social media on corporate greenwash. J. Bus. Ethics 118:747757. https://doi.org/10.1007/s10551-013-1958-x.

Markova-Nenova, N., and F. Wätzold. 2018. Fair to the cow or fair to the farmer? The preferences of conventional milk buyers for ethical attributes of milk. Land Use Policy 79:223-239. https://doi.org/10 .1016/j.landusepol.2018.07.045.

McCarthy, K. S., M. Parker, A. Ameerally, S. L. Drake, and M. A. Drake. 2017. Drivers of choice for fluid milk versus plant-based alternatives: What are consumer perceptions of fluid milk? J. Dairy Sci. 100:6125-6138. https://doi.org/10.3168/jds.2016-12519.

Merlino, V., and S. Blanc. 2019. Does the organic certification influence the purchasing decisions of milk consumers? Quality 20:382387.

Mintel Group Ltd. 2019a. Milk and Non-Dairy Milk - US - October 2019. Accessed Dec. 19, 2019. https://academic.mintel.com/ display/919346/. 
Mintel Group Ltd. 2019b. Cheese - US - October 2019. Accessed May 5, 2020. https://academic.mintel.com/display/919976.

Napolitano, F., A. Girolami, and A. Braghieri. 2010. Consumer liking and willingness to pay for high welfare animal-based products. Trends Food Sci. Technol. 21:537-543. https://doi.org/10.1016/j .tifs.2010.07.012.

Peano, C., V. M. Merlino, F. Sottile, D. Borra, and S. Massaglia. 2019. Sustainability for food consumers: Which perception? Sustainability 11:5955. https://doi.org/10.3390/su11215955.

Pelletier, J. E., M. N. Laska, D. Neumark-Sztainer, and M. Story. 2013. Positive attitudes toward organic, local, and sustainable foods are associated with higher dietary quality among young adults. J. Acad. Nutr. Diet 113:127-132. https://doi.org/10.1016/ j.jand.2012.08.021.

Plant Based Foods Association. 2018. Plant-based foods sales grow 20 percent. New Nielsen retail data commissioned by the plant based foods association shows plant-based alternatives outpacing overall food sales by 10X. Accessed Dec. 19, 2019. https:// plantbasedfoods.org/wp-content/uploads/2018/07/PBFA-Release -on-Nielsen-Data-7.30.18.pdf.

Rässler, S., and R. T. Riphahn. 2006. Survey item nonresponse and its treatment. All. Stat. Arch. 90:217-232.

Sautron, V., S. Péneau, G. M. Camilleri, L. Muller, B. Ruffieux, S. Hercberg, and C. Méjean. 2015. Validity of a questionnaire measuring motives for choosing foods including sustainable concerns. Appetite 87:90-97. https://doi.org/10.1016/j.appet.2014.12.205.

Schuldt, J. P., D. Muller, and N. Schwarz. 2012. The "fair trade" effect: Health halos from social ethics claims. Soc. Psychol. Personal. Sci. 3:581-589. https://doi.org/10.1177/1948550611431643.

Speight, K., A. N. Schiano, W. S. Harwood, and M. A. Drake. 2019. Consumer insights on prepackaged Cheddar cheese shreds using focus groups, conjoint analysis, and qualitative multivariate analysis. J. Dairy Sci. 102:6971-6986. https://doi.org/10.3168/jds.2018 $-16209$.

Thompson, J. L., P. D. Gerard, and M. A. Drake. 2007a. Chocolate milk and the Hispanic consumer. J. Food Sci. 72:S666-S675. https: //doi.org/10.1111/j.1750-3841.2007.00559.x.

Thompson, J. L., K. Lopetcharat, and M. A. Drake. 2007b. Preferences for commercial strawberry drinkable yogurts among African American, Caucasian, and Hispanic consumers in the United States. J. Dairy Sci. 90:4974-4987. https://doi.org/10.3168/jds .2007-0313.

Toptal, I., S. Nart, C. Akar, and A. Erkollar. 2019. The effect of greenwashing on online consumer engagement: A comparative study in France, Germany, Turkey, and the United Kingdom. Bus. Strategy Environ. 2019:1-6.

United Nations Department of Economic and Social Affairs. 2015. Transforming our world: The 2030 agenda for sustainable development. Accessed Dec. 19, 2019. https://sustainabledevelopment .un.org/content/documents/21252030\%20Agenda\%20for $\% 20$ Sustainable\%20Development\%20web.pdf.

van Dam, Y. K., and H. C. M. van Trijp. 2011. Cognitive and motivational structure of sustainability. J. Econ. Psychol. 32:726-741. https://doi.org/10.1016/j.joep.2011.06.002.

Verain, M. C. D., J. Bartels, H. Dagevos, S. J. Sijtsema, M. C. Onwezen, and G. Antonides. 2012. Segments of sustainable food consumers: A literature review. Int. J. Consum. Stud. 36:123-132.

Verain, M. C. D., S. J. Sijtsema, and G. Antonides. 2016. Consumer segmentation based on food-category attribute importance: The relation with healthiness and sustainability perceptions. Food Qual. Prefer. 48:99-106. https://doi.org/10.1016/j.foodqual.2015 .08 .012

\section{ORCIDS}

P. D. Gerard ๑ https://orcid.org/0000-0003-3710-6055 M. A. Drake 난 https://orcid.org/0000-0002-4744-2493

\section{APPENDIX}

\section{Sustainability Focus Group Moderator Guide}

\section{Respondent Introductions}

Introduce yourself and share your online pinboard.

\section{Focus Area 1: Involvement with Sustainability}

1) What dairy products and non-dairy alternative products do you buy?

2) How important is sustainability to you as a consumer? What aspects of your life does your desire for sustainability influence?

3) How knowledgeable would you say you are on the topic of sustainability?

4) What does sustainability mean to you?

5) What are your main suitability concerns?

\section{Focus Area 2: Corporate Branding}

1) How does a company show a commitment to sustainability?

2) Do you trust companies when they claim to care about sustainability?

3) What sources of information do you look to when deciding whether to trust a company?

a. Ex: packaging, website, social media, bloggers, company advertisements, company annual report, in-store information, recommendations, non-profit consumer advocates, and special interest organizations

4) Is it more important for a product to be sustainable, or for a company to show a commitment to sustainability?

5) Opinions of large companies with sustainable product lines vs. small companies selling only sustainable products

\section{Term Categorization Exercise}

Give consumers stacks of sticky notes with the following terms. Ask them to categorize each term into one of these categories by sticking it on the board under the chosen label: "Required for Sustainability," "Contributes to but Not Required for Sustainability," "Misleading," and "I don't understand/am not familiar with this term."

Terms: eco-friendly packaging, animal happiness, locally produced, animal wellness, animal feed (grass, grain, etc.), fair trade, resource cycling, certifications (Fair Trade, Rainforest Alliance, Validus, etc.), ethical- 
ly sourced, ecological balance, good for/doesn't harm wildlife, brand narrative, minimal cold chain, reasonably priced, employees paid fairly, all products from company are sustainable, water conservation, simple/ minimal ingredients, minimal carbon footprint, heathy, pesticide-free, ownership transparency, recyclable packaging, non-GMO, charitable donations, plant-based, shelf-stable, biodegradable packaging, all-natural, produced by large company.

\section{Elaborating on Categorization Exercise}

1. Why did you categorize each term as you did?

2. How does the presence or absence of these attributes influence your purchase of dairy products?
3. Are there any terms on here that you see on dairy product packages that you find misleading or questionable? Why do you feel this way?

4. Are there any terms on this list that you do not understand but frequently see on dairy product packages? Why do you think these terms are included?

\section{Wrap-Up}

Inquire as to any final thoughts. 